\title{
Adalimumab (a fully human anti-tumour necrosis factor $\alpha$ monoclonal antibody) in the treatment of active rheumatoid arthritis: the initial results of five trials
}

\section{R Rau}

$R^{\prime}$ heumatoid arthritis (RA), a common, chronic, idiopathic autoimmune disease, is characterised by symmetrical synovitis, inflammatory exudates in the joint cavity, and erosion of articular cartilage and marginal bone. ${ }^{1}$ Standard treatment for RA typically consists of traditional disease modifying antirheumatic drugs (DMARDs), corticosteroids, non-steroidal anti-inflammatory drugs, and analgesics. ${ }^{2}$ Despite these various treatments, many patients with RA continue to experience substantial disease activity, with progressive joint damage and accompanying functional loss. In recent years, insights into the pathophysiology of RA have lead to the development of novel therapeutic strategies that target underlying disease processes, the most promising of which entails neutralisation of tumour necrosis factor $\alpha$ $(\mathrm{TNF} \alpha){ }^{3}$

\section{ANTI-TNF $\alpha$ TREATMENTS}

$\mathrm{TNF} \alpha$ is a potent proinflammatory cytokine that plays a critical part in the progression of inflammatory synovitis and articular matrix degradation in RA. ${ }^{3}$ Increased concentrations of TNF $\alpha$ are found in the synovial fluid and serum of patients with active RA. ${ }^{4}$ Derived primarily from activated monocytes and macrophages, TNF $\alpha$ promotes the synthesis of other proinflammatory cytokines; stimulates endothelial cells to express adhesion molecules that attract leucocytes into affected joints; accelerates the production of metalloproteinases by synovial macrophages, fibroblasts, osteoclasts, and chondrocytes; and suppresses the synthesis of cartilage proteoglycans. ${ }^{356}$ Because of these multiple actions, TNF $\alpha$ may have a more dominant function in the pathogenesis of RA than other proinflammatory cytokines such as interleukin $1 .{ }^{3}$ The effects of TNF $\alpha$ are triggered by its binding to two different membrane receptors (p55 and p75) that are expressed by certain cell types, including neutrophils, vascular endothelial cells, and fibroblasts.

Over the past two decades, investigators have not only delineated the spectrum of pathological actions of TNF $\alpha$ but also devised ways of effectively blocking this cytokine, offering renewed hope to patients with refractory, moderate to severe RA. ${ }^{3}$ Currently, two biologically based DMARDs that inactivate $\mathrm{TNF} \alpha$ are commercially available for treating RA. One is infliximab, a chimeric ( $75 \%$ human and $25 \%$ mouse peptide sequences) anti-TNF $\alpha$ monoclonal antibody, and the other is etanercept, a recombinant human TNF receptor (p75)-Fc artificial fusion protein. ${ }^{8}$ Etanercept is administered subcutaneously twice weekly, ${ }^{9}$ whereas infliximab is given intravenously every two months and only in combination with methotrexate (MTX).$^{10}$ A potential new addition to the class of biological DMARDs, adalimumab (D2E7, Abbott Laboratories) is the first fully human (100\% human peptide sequences) antiTNF $\alpha$ monoclonal antibody to be investigated for the treatment of RA. ${ }^{11-16}$

\section{ADALIMUMAB}

Engineered through guided selection techniques (phage display technology), a method that mimics natural immunoglobulin gene rearrangement, adalimumab contains neither non-human components nor artificially fused human peptide sequences. ${ }^{11}$ As such, adalimumab is indistinguishable in structure and function from naturally occurring human immunoglobulin Gl (IgGl) and has a terminal half life comparable to that of human IgGl (approximately two weeks). ${ }^{11}$ Possessing a high specificity and affinity for TNF $\alpha$ $\left(\mathrm{kDa}=6 \times 10^{-10} \mathrm{M}\right)$ but not other cytokines, such as TNF $\beta$ (lymphotoxin), adalimumab exerts its therapeutic effects by blocking the interaction of TNF $\alpha$ with the p55 and p75 receptors. ${ }^{11}$ Adalimumab was developed to have low immunogenicity, avoiding the need for concomitant administration with immunosuppressants such as MTX. Adalimumab underwent an extensive clinical development programme consisting of phase I safety and tolerability studies, phase II dose ranging studies, and phase III confirmatory safety and efficacy studies. This review highlights data from five clinical studies with adalimumab, specifically DE001/003, DE004, DE007, DE009, and DE010.

\section{ADALIMUMAB TRIAL RESULTS}

These studies used various designs to vigorously evaluate the therapeutic potential of adalimumab among patients with RA (table 1). All these trials enrolled patients with longstanding RA who had active disease that was refractory to several previous traditional DMARDs. Efficacy was assessed using standard composite criteria, such as the American College of Rheumatology (ACR) response criteria, ${ }^{17}$ European League Against Rheumatism (EULAR) response criteria, ${ }^{18}$ based on the Disease Activity Score (DAS). ${ }^{18}$ ACR responses were categorised as $20 \%, 50 \%$, and $70 \%$ improvements (ACR20, ACR50, and ACR70). ${ }^{17}$ At the time of this review, data from these studies had been presented only in abstract form and, therefore, should be considered preliminary.

DE001/003 was a phase I study that evaluated the safety, tolerability, and pharmacokinetics of single (DE001) and multiple (DE003) intravenous injections of various doses of adalimumab in patients $(n=120)$ with active RA who were refractory to previous traditional DMARD treatment. ${ }^{19}$ This study was the first clinical experience with adalimumab. Patients were initially randomised to receive a single intravenous injection of adalimumab $0.5,1.0,3.0,5.0$, or $10.0 \mathrm{mg} / \mathrm{kg}$ or placebo. The second intravenous dose was applied when patients lost their response but not before four weeks after the first injection. After the second dose, placebo treated patients

Abbreviations: RA, rheumatoid arthritis; $\mathrm{TNF} \alpha$, tumour necrosis factor $\alpha ;$ MTX, methotrexate; DMARD, disease modifying antirheumatic drug 


\begin{tabular}{|c|c|c|c|c|c|c|c|}
\hline Study & Phase & Design & Patients & Adalimumab doses & $\begin{array}{l}\text { Concomitant } \\
\text { DMARD }\end{array}$ & $\begin{array}{l}\text { Treatment } \\
\text { duration }\end{array}$ & Study sites \\
\hline DE001/003 & 1 & $\begin{array}{l}\text { Randomised, double blind, placebo controlled for } \\
\text { first and second injection, and open label } \\
\text { thereafter }\end{array}$ & $\begin{array}{l}\text { Patient number }=120 \\
\text { Mean disease duration }=11.5 \mathrm{y} \\
\text { Mean DAS }=5.3 \\
\text { Mean previous DMARDs }=3.9\end{array}$ & Adalimumab 0.5 to $10.0 \mathrm{mg} / \mathrm{kg}$ iv every 2 weeks & None & 12 months & Europe \\
\hline DE004 & 1 & $\begin{array}{l}\text { Randomised, double blind, placebo controlled for } \\
\text { first } 3 \text { months and open label for next } 3 \text { months }\end{array}$ & $\begin{array}{l}\text { Patient number }=24 \\
\text { Mean disease duration }=10.1 \text { y } \\
\text { Mean DAS }=5.3 \\
\text { Mean } \mathrm{SJC}=19.9 \\
\text { Mean } \mathrm{TJC}=21.4\end{array}$ & Adalimumab $0.5 \mathrm{mg} / \mathrm{kg} \mathrm{sc}$ weekly & None & 6 months & Europe \\
\hline DEO07 & $\|$ & Randomised, double blind, placebo controlled & $\begin{array}{l}\text { Patient number }=283 \\
\text { Median age }=53 \text { y } \\
\text { Median disease duration }=8 \text { y } \\
\text { Median } S J C=18 \\
\text { Median TJC }=30 \\
\text { Median } E S R=45 \mathrm{~mm} / \mathrm{h} \\
\text { Median } C R P=5.1 \mathrm{mg} / \mathrm{dl} \\
\text { Median previous DMARDs }=4\end{array}$ & Adalimumab $20 \mathrm{mg}, 40 \mathrm{mg}$, or $80 \mathrm{mg}$ sc weekly & None & 12 weeks & Europe \\
\hline DEO09 & $\|$ & Randomised, double blind, placebo controlled & $\begin{array}{l}\text { Patient number }=271 \\
\text { Mean age }=55.1 \mathrm{y} \\
\text { Mean disease duration }=12.3 \mathrm{y} \\
76.8 \% \text { female } \\
81 \% \text { RF positive } \\
\text { Mean SJC }=17.2 \\
\text { Mean TJC }=28.9 \\
\text { Mean CRP }=2.7 \mathrm{mg} / \mathrm{dl} \\
\text { Mean } \mathrm{HAQ}=1.6 \\
\text { Mean previous DMARDs }=3 \\
\text { Mean MTX dose }=16.8 \mathrm{mg} / \mathrm{wk}\end{array}$ & Adalimumab $20 \mathrm{mg}, 40 \mathrm{mg}$, or $80 \mathrm{mg}$ sc every other week & MTX & 24 weeks & North America \\
\hline DE010 & 1 & $\begin{array}{l}\text { Randomised, double blind, placebo controlled for } \\
\text { first and second injection and open label } \\
\text { thereafter }\end{array}$ & $\begin{array}{l}\text { Patient number }=54 \\
\text { Median DAS }=4.72 \\
\text { Median Ritchie Index }=16.0 \\
\text { Median SJC }=19.0 \\
\text { Mean MTX dose }=16.0 \mathrm{mg} / \mathrm{wk}\end{array}$ & Adalimumab $1.0 \mathrm{mg} / \mathrm{kg}$ sc or iv weekly to monthly & MTX & 24 months & Europe \\
\hline
\end{tabular}




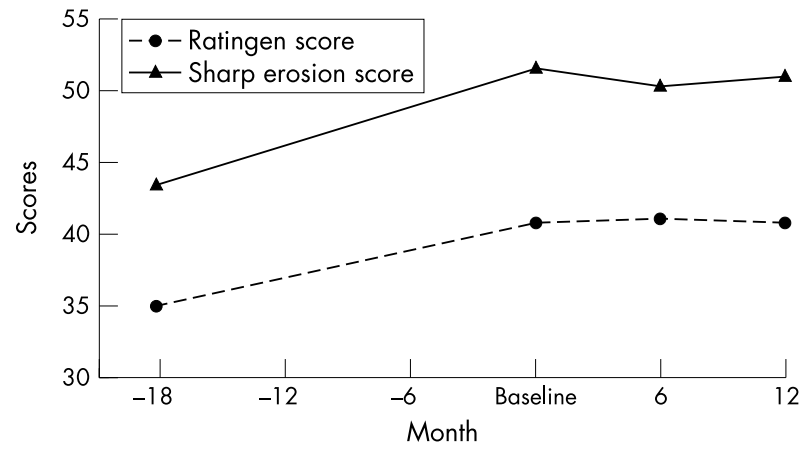

Figure 1 Radiological scores for patients with prestudy radiographs $(n=29)$ in DEO01/003.

were randomly assigned to one of the adalimumab doses, and all patients were treated on an open label basis. Dose escalation was permitted in patients treated with adalimumab $0.5 \mathrm{mg} / \mathrm{kg}$ or $1.0 \mathrm{mg} / \mathrm{kg}$. Adalimumab was administered every two weeks until achieving good response according to EULAR response criteria with an absolute DAS value less than 2.4. Subsequently, patients were re-treated only when the DAS value increased to above 2.4 again. The mean adalimumab dose interval was 2.5 weeks. Adalimumab was well tolerated in this study. The safety profile of a single dose of adalimumab was comparable to that of placebo. Over the 12 month period, 12 patients dropped out: six patients because of lack of efficacy, five because of adverse events, and one because of patient's request. Responder status (as defined by a decrease of at least 1.2, compared with baseline, in DAS value) was achieved and sustained by more than $80 \%$ of patients. Swollen joint count and tender joint count were reduced by about $60 \%$. Pharmacokinetic parameters were proportional to adalimumab dose, with the mean maximum plasma concentration of adalimumab ranging from $25 \mu \mathrm{g} / \mathrm{ml}$ to $284 \mu \mathrm{g} / \mathrm{ml}$ and the mean area under the time concentration curve ranging from 2729 to $67115 \mu \mathrm{g} \mathrm{g} \times \mathrm{h} / \mathrm{ml}^{20}{ }^{20}$ The mean total serum clearance was 0.012 to $0.017 \mathrm{l} / \mathrm{h}$, and the volume of distribution ranged from 0.068 to $0.082 \mathrm{l} / \mathrm{kg}$, indicating that adalimumab was distributed mostly in the intravascular space. The mean terminal half life of adalimumab was 10.0 to 13.6 days. ${ }^{20}$

In DE001/DE003, the arrest of radiographic disease progression with adalimumab treatment was demonstrated in a subset of 66 patients from the extension study who had a complete set of radiographs available taken at baseline, six, and 12 months of treatment. ${ }^{21}$ Among this cohort were 29 patients who had pretreatment radiographs available from a mean of 18 months before starting treatment. Pretreatment radiographic progression was substantial in this group of patients with longstanding RA despite traditional DMARD treatment. After one year of adalimumab treatment, however, no further evidence of radiographic progression could be detected in these patients as evidenced by stabilisation in Ratingen and Sharp erosion scores ( fig l).

DE004 was a phase I, six month study that evaluated the safety and tolerability of subcutaneous injections of adalimumab monotherapy in patients $(n=24)$ with active RA who were refractory to previous traditional DMARD treatment. ${ }^{22}$ Patients were randomised to receive adalimumab $0.5 \mathrm{mg} / \mathrm{kg}$ subcutaneously weekly or placebo for three months in a double blind manner. Thereafter, all patients continued on open label adalimumab. Non-responders (a reduction in DAS of less than 1.2 compared with baseline) or patients who lost their responder status received adalimumab $1.0 \mathrm{mg} / \mathrm{kg}$ subcutaneously weekly. After six months of treatment, there were mean reductions in DAS, tender joint count, and swollen joint count of approximately $50 \%, 60 \%$, and $70 \%$, respectively. Adalimumab was well tolerated in this limited group of patients.
Plasma concentrations of adalimumab after multiple subcutaneous injections were comparable with those after intravenous injections.

DE007 was a phase II, 12 week, double blind, placebo controlled study that evaluated the efficacy, dose response effect, safety, and tolerability of subcutaneous injections of adalimumab monotherapy in patients $(n=283)$ with active RA who were refractory to previous traditional DMARD treatment. ${ }^{23}$ After treatment with all traditional DMARDs had been stopped, patients were randomised to receive subcutaneous injections of adalimumab $20 \mathrm{mg}, 40 \mathrm{mg}$, or $80 \mathrm{mg}$ weekly or placebo. At week 12, ACR20 response rates for adalimumab 20 $\mathrm{mg}, 40 \mathrm{mg}$, and $80 \mathrm{mg}$ (49\%, 57\%, and 56\%, respectively) were significantly greater than that for placebo $(10 \%)(p \leqslant 0.001$ for each comparison). Improvements in ACR20 response rates were maintained over the 12 week period. Each of the ACR core criteria significantly improved with each adalimumab dose. Adalimumab generally was well tolerated, with most adverse events being mild or moderate. The three doses of adalimumab were similarly well tolerated, the $40 \mathrm{mg}$ and 80 $\mathrm{mg}$ doses were equally effective while the $20 \mathrm{mg}$ dose was somewhat less effective. The results of DE007 demonstrated that adalimumab treatment produces rapid, sustained responses and is safe and well tolerated, with no dose limiting side effects.

DE009, also known as the ARMADA (Anti-TNF Research Study Program of the Monoclonal Antibody Adalimumab [D2E7] in Rheumatoid Arthritis) trial, was a phase II/III, 24 week, double blind, placebo controlled study that evaluated the efficacy, safety, and tolerability of adalimumab in patients $(n=271)$ with active RA who partially responded to MTX treatment. ${ }^{24}$ After discontinuation of all traditional DMARDs except MTX, patients were randomised to receive injections of adalimumab $20 \mathrm{mg}, 40 \mathrm{mg}$, or $80 \mathrm{mg}$ subcutaneously every other week or placebo while continuing on stable chronic MTX. At week 24, an ACR20 response was achieved by a significantly greater proportion of patients in the $20 \mathrm{mg}, 40$ $\mathrm{mg}$, and $80 \mathrm{mg}$ adalimumab plus MTX groups $(47.8 \%, 65.7 \%$, and $65.8 \%$, respectively) than in the placebo plus MTX group (14.5\%) ( $\mathrm{p}<0.001$ for each comparison). ACR50 response rates with the $20 \mathrm{mg}, 40 \mathrm{mg}$, and $80 \mathrm{mg}$ adalimumab doses plus MTX $(31.9 \%, 53.7 \%$, and $42.5 \%$, respectively) were significantly greater than that with placebo plus MTX $(8.1 \%)$ $(\mathrm{p}=0.003, \mathrm{p}<0.001$, and $\mathrm{p}<0.001$, respectively $)$. The $40 \mathrm{mg}$ and the $80 \mathrm{mg}$ doses of adalimumab plus MTX were associated with ACR70 response rates (26.9\% and $19.2 \%)$ that was statistically significantly greater than that with placebo plus MTX $(4.8 \%) \quad(p=0.020$ for each comparison). Such ACR50 and ACR70 response rates are impressive for a group of patients with severe refractory RA. Adalimumab was safe and well tolerated, with comparable numbers of adalimumab treated and placebo treated patients reporting adverse events. Injection site reactions occurred in $15.3 \%$ of adalimumab treated patients compared with $3.2 \%$ of placebo treated patients. There were 18 withdrawals (nine from the placebo group and nine from the adalimumab groups), eight related to adverse events and 10 for lack of efficacy or administrative reasons. The results of DE009 demonstrated that the efficacy of adalimumab (20 mg, $40 \mathrm{mg}$, or $80 \mathrm{mg}$ ) given subcutaneously every other week in combination with MTX is significantly better than MTX alone, and that adalimumab may be a therapeutic option for patients with active RA who are partially responsive to MTX.

DE010 was a phase I, open labelled study that evaluated the pharmacokinetics, safety, and tolerability of intravenous and subcutaneous administration of adalimumab in patients $(n=54)$ with longstanding, active RA with insufficient efficacy or tolerability with MTX alone. ${ }^{25}$ After discontinuation of all traditional DMARDs except MTX, patients were initially randomised to receive injections (first and second injections) of adalimumab $1 \mathrm{mg} / \mathrm{kg}$ subcutaneously, adalimumab $1 \mathrm{mg} / \mathrm{kg}$ 
intravenously, or placebo (double dummy). Thereafter, all patients received open label subcutaneous injections of 1 $\mathrm{mg} / \mathrm{kg}$ of adalimumab every other week up to every other month, depending on patient response. At month 24, adalimumab therapy achieved EULAR, ACR20, and ACR50 responses rates of $78 \%, 50 \%$, and 30\%, respectively. Median DAS, Ritchie Index, and swollen joint count were $2.58,4.5$, and 4.5 , respectively. During the initial double blind study period, adverse events were similar between the adalimumab and placebo groups. A total of 44 patients (81\%) completed the two year study period. Reasons for withdrawal included adverse events (six patients), lack of efficacy (two patients), death (one patient; myocardial infarction), and protocol violation (one patient). DE010 demonstrated that repeated subcutaneous injections of $1 \mathrm{mg} / \mathrm{kg}$ adalimumab over a period of two years provides sustained efficacy and is well tolerated when given in combination with stable standard doses of MTX in patients with active RA.

\section{CONCLUSIONS}

Taken together, these preliminary phase I and phase II results indicate that adalimumab, the first fully human anti-TNF $\alpha$ monoclonal antibody, is effective at reducing signs and symptoms of RA. In these studies, adalimumab had a rapid onset of action and sustained efficacy. Furthermore, adalimumab was safe and effective when given alone or in combination with MTX as a subcutaneous injection. Additional studies are underway to futher define the optimal use of this promising therapeutic option for RA.

\section{Author's affiliations}

R Rau, Department of Rheumatology, Evangelisches Fachkrankenhaus Ratingen, Ratingen, Germany

Correspondence to: Dr R Rau, Rheumaklinik, Evangelisches Fachkrankenhaus, Rosenstr 2 D-40882 Ratingen, Germany; rrau@uni-duesseldorf.de

\section{REFERENCES}

1 Lee DM, Weinblatt ME. Rheumatoid arthritis. Lancet 2001;358:903-11.

2 American College of Rheumatology Subcommittee on Rheumatoid Arthritis Guidelines. Guidelines for the management of rheumatoid arthritis: 2002 update. Arthritis Rheum 2002;46:328-46.

3 Choy EH, Panayi GS. Cytokine pathways and joint inflammation in rheumatoid arthritis. N Engl J Med 2001;344:907-16

4 Saxne T, Palladino MA Jr, Heinegard D, Talal N, Wollheim FA. Detection of tumor necrosis factor alpha but not tumor necrosis factor beta in rheumatoid arthritis synovial fluid and serum. Arthritis Rheum 1988;31:1041-5.

5 Nedwin GE, Bringman TS, Smith DD, Mundy GR. Stimulation of bone resorption and inhibition of bone formation in vitro by human tumour necrosis factors, Nature 1986:319:516-18.

6 Saklatvala J. Tumour necrosis factor alpha stimulates resorption and inhibits synthesis of proteoglycan in cartilage. Nature 1986;322:547-9.
7 Elliott MJ, Maini RN, Feldmann M, et al. Randomised double-blind comparison of chimeric monoclonal antibody to tumour necrosis factor alpha (cA2) versus placebo in rheumatoid arthritis. Lancet 1994;344:1105-10.

8 Moreland LW, Baumgartner SW, Schiff MH, et al. Treatment of rheumatoid arthritis with a recombinant human tumor necrosis factor receptor (p75)-Fc fusion protein. N Engl J Med 1997;337:141-7.

9 Enbrel (etanercept) [package insert]. Seattle, WA: Immunex Corporation, 2000

10 Remicade (infliximab) [package insert]. Malvern, PA: Centocor Inc, 1999.

11 Salfeld J, Kaymakçalan Z, Tracey D, Roberts A, Kamen R. Generation of fully human anti-TNF antibody D2E7. [Abstract]. Arthritis Rheum 1998;41 (suppl):S57.

12 Kempeni J. Preliminary results of early clinical trials with the fully human anti-TNF $\alpha$ monoclonal antibody D2E7. Ann Rheum Dis 1999;58 (suppl):170-2.

13 Kempeni J. Update on D2E7: a fully human anti-tumour necrosis factor $\alpha$ monoclonal antibody. Ann Rheum Dis 2000;59 (suppl): 144-5.

14 Barrera P, Joosten LA, den Broeder AA, et al. Effects of treatment with a fully human anti-tumour necrosis factor $\alpha$ monoclonal antibody on the local and systemic homeostasis of interleukin 1 and TNF $\alpha$ in patients with rheumatoid arthritis. Ann Rheum Dis 2001;60:660-9.

15 den Broeder AA, Joosten LA, Saxne T, et al. Long term anti-tumour necrosis factor alpha monotherapy in rheumatoid arthritis: effect on radiological course and prognostic value of markers of cartilage turnover and endothelial activation. Ann Rheum Dis 2002;61:311-18.

16 Barrera $\mathbf{P}$, van Der Maas A, van Ede AE, et al. Drug survival, efficacy and toxicity of monotherapy with a fully human anti-tumour necrosis factor-alpha antibody compared with methotrexate in long-standing rheumatoid arthritis. Rheumatology (Oxford) 2002:41:430-9.

17 Felson DT, Anderson JJ, Boers M, et al. The American College of Rheumatology preliminary core set of disease activity measures for rheumatoid arthritis clinical trials. Arthritis Rheum 1993;36:729-40.

18 van Gestel AM, Prevoo ML, van't Hof MA, et al. Development and validation of the European League Against Rheumatism response criteria for rheumatoid arthritis. Arthritis Rheum 1996;39:34-40.

19 Breedveld FC, Allaart CF, Rau R, et al. The fully human anti-TNF antibody adalimumab (D2E7) in combination with methotrexate (MTX) in the treatment of active rheumatoid arthritis: results of a 2-year study. Ann Rheum Dis 2001;60 (suppl I):OP 0062

20 den Broeder A, van de Putte LBA, Rau R, Schattenkirchner M, van Riel PLCM, Sander O, et al. A single-dose, placebo-controlled study of the fully human anti-TNF antibody adalimumab (D2E7) in patients with rheumatoid arthritis. J Rheumatol (in press).

21 Rau R, Herborn G, Sander O, van de Putte LBA, van Riel PLC, den Broeder $A$, et al. Long-term treatment with the fully human anti-TNF-antibody D2E7 slows radiographic disease progression in rheumatoid arthritis. [Abstract]. Arthritis Rheum 1999:42 (suppl):S400.

22 Schattenkirchner M, Krüger K, Sander O, Rau R, Kroot E-J, van Riel PLCM, et al. Efficacy and tolerability of weekly subcutaneous injections of the fully human anti-TNF-antibody D2E7 in patients with rheumatoid arthritis - results of a phase I study. [Abstract]. Arthritis Rheum 1998;41 (suppl):S57.

23 van de Putte L BA, Rau R, Breedveld FC, et al. Efficacy of the fully human anti-TNF antibody D2E7 in rheumatoid arthritis. [Abstract]. Arthritis Rheum 1999;42 (suppl):S400.

24 Keystone E, Weinblatt M, Furst D, et al. The ARMADA trial: a double-blind placebo controlled trial of the fully human anti-TNF monoclonal antibody, adalimumab (D2E7), in patients with active RA on methotrexate (MTX). [Abstract]. Arthritis Rheum 2001;44 (suppl):S213.

25 Rau R, Sander O, den Broeder A, et al. Long-term efficacy and tolerability of multiple I.V. doses of the fully human anti-TNF-antibody D2E7 in patients with rheumatoid arthritis. [Abstract]. Arthritis Rheum 1998;41 (suppl):S55 